\title{
lodine adsorption characteristics of activated carbon obtained from Spinacia oleracea (spinach) leaves
}

\author{
Prakash Kumar Jha and Vinay Kumar Jha* \\ Central Department of Chemistry, Tribhuvan University, Kirtipur, Kathmandu, Nepal \\ *Corresponding author: vinayj2@yahoo.com; ORCID iD:0000-0001-6375-8482
}

Received: 5 January 2020; revised: 24 April 2020; accepted: 30 April 2020

\begin{abstract}
Spinach leaves powder was modified by activation with conc. $\mathrm{H}_{2} \mathrm{SO}_{4}$ and characterized by using FTIR, optical microscopy, $\mathrm{XRD}$ analysis, and methylene blue adsorption method. The maximum specific surface area measured by the Methylene blue adsorption method was $499 \mathrm{~m}^{2} / \mathrm{g}$. The adsorption of iodine was investigated by varying parameters like $\mathrm{pH}$, adsorbent dose, contact time, and $\mathrm{I}_{2}$ concentration. The adsorption process was fitted to the Langmuir model controlled by pseudo second - order kinetics with a constant rate value of $0.00305 \mathrm{~g} /(\mathrm{mg} \cdot \mathrm{min})$. The maximum adsorption capacity was 909.091 $\mathrm{mg} / \mathrm{g}$ at $\mathrm{pH} 10$. The $\Delta \mathrm{G}$ value was $-25 \mathrm{~kJ} / \mathrm{mol}$, which confirmed the physico - chemcal adsorption process.
\end{abstract}

Keywords: Acid - activated carbon; Adsorption; lodine; Spinach leaves; Waste.

\section{INTRODUCTION}

The earthquake, tsunami and subsequent nuclear accident at Fukushima in March 2011 further emphasized the importance of getting timely and technically sound information (such as transport and the fate of radionuclides, potential doses, and risks, etc.) for decision making in emergency response as well as in cleanup and recovery for both humans and their environment [1]. A large quantity of radioactivity in Fukushima's environment was caused due to the nuclear power plant accident [2]. A positive relationship was seen between the clay content of topsoil (upper $2.0 \mathrm{~cm}$ ) and mass relaxation depth of ${ }^{131}$ I (i.e., $86 \%$ of total ${ }^{131}$ I were adsorbed at the topsoil). Bioaccumulation of ${ }^{131}$ I was observed to be more in spinach at the accidental place of Fukushima. The level of ${ }^{131} \mathrm{I}$ in Fukushima's spinach was more than seven times the safe level [3]. A study on investigation of contamination in spinach collected immediately following the Fukushima Daiichi nuclear disaster identified that the radionuclides deposited in the spinach were ${ }^{132} \mathrm{Te},{ }^{131} \mathrm{I},{ }^{134} \mathrm{Cs},{ }^{136} \mathrm{Cs}$, and ${ }^{137} \mathrm{Cs}$. Only $40 \%$ of these radionuclides were removed when the spinach was washed with water or detergents. The concentration of radionuclide was more prominent in two outer leaves. Radioactivity concentration of epidermal tissue was observed to be nine times that of mesophyll tissue [4]. lodine is an essential component of the thyroid hormones thyroxine (T4) and triiodothyronine (T3). Thyroid hormones regulate many important biochemical reactions, including protein synthesis and enzymatic activity, and are critical determinants of metabolic activity. They are also required for proper skeletal and central nervous system development in fetuses and infants [5]. In infants and children, less severe iodine deficiency can also cause neurodevelopmental deficits. In adults, mild to moderate iodine deficiency can cause goiter and impaired mental function and work productivity from secondary to hypothyroidism. Chronic iodine deficiency may be associated with an increased risk of the follicular form of thyroid cancer [6]. The different sources for brines containing iodine at different extent include oil and gas field wastes, seawater or effluent from seawater desalination plant or, other inland brine sources. Several non - radioactive forms of iodine in an aqueous system include $\mathrm{I}_{2}, \mathrm{I}$, and $\mathrm{I}_{3}$. Since the iodine ions are distributed widely in aquatic environments at very low concentrations, the development of new technology and engineering strategies for remediation of iodine ions is critical. Due to the same reasons, chemical methods such as precipitation are not used effectively for the removal of iodine ions [7]. Indian spinach called Spinacia Oleracea is eaten by people mainly for its characteristics green color, nutritional contents such as carotenes, vitamin C, and minerals such as calcium and iron [8]. Bio-chars are used as the most effective adsorbent for iodine and other metallic non-metallic hazardous ions removal from earlier days [9].

(C) The Author(s). 2020 Open access. This article is distributed under the terms of the Creative Commons Attribution 4.0 International License (http://creativecommons.org/licenses/by/4.0/), which permits unrestricted use, distribution, and reproduction in any medium, provided you give appropriate credit to the original author(s) and the source, provide a link to the Creative Commons license, and indicate if changes were made. 
A study for lodine recovery processes utilized various types of adsorbents for recovery purposes. Adsorption of iodine on activated carbon was generally expected in the form of $\mathrm{I}_{2}$. Activated coconut carbon particles were used to adsorb iodide through its pores. Alumina impregnated with copper and chromium oxides was used as adsorbent material for the recovery of iodine in both aqueous and gas phases. Strongly basic anion exchange resin and activated carbon particles were used as adsorbent materials to recover iodine from brines. The recent topic of excitement for most researchers was to recover iodine from aqueous solution with low-cost adsorbent materials instead of highly expensive ion exchange resins [10 - 16]. A study for the adsorption of $\mathrm{Cr}$, $\mathrm{Sr}$, and I on microalgae and aquatic plants showed that among 188 strains examined from microalgae, aquatic plants, and unidentified algae species, five strains were selected as highly positive radioactive eliminators for iodine ions. The maximum elimination of radioactive iodine was $66 \%$ by the Nostoc Commune Tir4 strain [7]. A study for iodine recovery by a granulated activated carbon from diluted aqueous solutions, such as natural brines and bitterns, examines its iodine extraction followed by desorption using sodium hydroxide solution. Maximum $97.5 \%$ iodine was adsorbed and showing a good fit with Freundlich adsorption isotherm under optimal conditions of $\mathrm{pH} 2$, agitation speed $200 \mathrm{rpm}$, particle size of carbon $0.5-1.2 \mathrm{~mm}$, carbon dosage $2 \mathrm{~g} / \mathrm{L}$, contact time 3 hours and initial concentration of iodine solution $30 \mathrm{ppm}$. Maximum desorption of 98.9 $\%$ was achieved under the optimal conditions of $\mathrm{NaOH}$ solution temperature $(0.5 \%) 55{ }^{\circ} \mathrm{C}$, agitation speed $300 \mathrm{rpm}$, contact time 6 hour, $\mathrm{NaOH}$ solution volume, and washing water volume 10 times the iodine solution volume and the maximum number of washing stages of 2. The iodine number of activated carbon used was 850 $\mathrm{mg} / \mathrm{g}$ [10]. A study for adsorption of iodine on nylon - 6 showed that nylon - 6 was imparted with antibacterial activity by adsorption of iodine. The amount of iodine adsorbed was found to be very high as compared to the theoretical amount of iodine required to form a single layer on the surface of fibers. lodine adsorption from solution in acetone did not follow Langmuir adsorption, but in case of adsorption of iodine from vapors, it was appeared to follow pseudo - Langmuir adsorption isotherm. In the vapor phase, iodine was adsorbed on nylon mainly in molecular form while in the presence of a solvent, iodine change to ionic form I- that may form complex with more iodine molecules to form polyiodide ions like $I_{3}^{-}, I_{5}^{-}$etc. [17]. A study for adsorption of iodine on cationic cross - linked starches investigated the optimal value of adsorption capacity of 4.54 and $4.61 \mathrm{mmol} / \mathrm{g}$ at a higher value of the degree of substitution 0.54 and the highest temperature $35^{\circ} \mathrm{C}$, in accordance with Langmuir adsorption isotherm for adsorption of iodine on cationic cross - linked starch chloride $(\mathrm{CCSCl})$ and cation cross - linked starch iodide (CCSI), respectively [18]. The ion exchange mechanism between anionic species of iodine and quaternary ammonium groups and favorability of iodine adsorption on both $\mathrm{CCSCl}$ and CCSI was confirmed by the calculated values of Dubinin - Radushkevich adsorption energy $E_{D R}$ and the Freundlich constant $n_{F}$ and was spontaneous process. The experimental data of iodine adsorption on cross - linked starch (CS) at equilibrium $\left(Q_{B, B X F}\right)$ varied from 0.20 to $0.29 \mathrm{mmol} / \mathrm{g}$ and was physical and was not suitably described by Langmuir adsorption modes. The Freundlich and Dubinin - Radushkevich adsorption models described the iodine adsorption on both cation-cross - linked starch (CCS) and cross - linked starch (CS) with the same approximation $\left(R_{2}>0.95\right)$ [18]. A study for the application of methylene blue and iodine adsorption in the measurement of specific surface area by four acid and salt treated activated carbons estimated, mesoporous structural parameters (SMB) in $10^{-3} \mathrm{~km}^{2} /$ $\mathrm{kg}$ to range between $14.545-15.100,13.548-14.011$, $12.313-13.970$ and $14.275-14.551$ for the groundnut shell (GS), shea nutshells (SS), poultry droppings (PD), and Poultry waste (PW) sorbents, respectively. Their corresponding micropore level and degree of activation were presented as iodine adsorption number (in $10^{-3}$ molar of iodine per gram of activated carbon) following the range of $2.156-2.171,2.174-2.191,2.163-2.193$ and 2.157 - 2.168. The data were widely different from those of their respective pyrolyzed materials and were only slightly lower than those of commercial reference carbon (SMB $15.627 \times 10^{-3} \mathrm{~km}^{2} / \mathrm{kg}$ and IAN $2.230 \mathrm{mmol} / \mathrm{g}$ ). In each case, it was seen that activation after carbonization further increased the total surface area. Generally, iodine number, surface area, degree of activation, and expected adsorption effectiveness in removal of small-sized adsorbate was seen higher in the case of smaller volume of iodine adsorbed, and the reverse was also true [19]. Improvisation of adsorption using low-cost adsorbent materials such as readily available agricultural waste and their physico-chemical modification in order to introduce surface functional groups is one of the most significant ways to enhance the adsorption efficiency of the adsorbent. Only a few studies concentrate on summarizing the various techniques used to produce activated carbon from spinach leaves. Therefore, in this study, acid-activated carbon prepared from the chemical treatment of spinach leaves powder with concentrated $\mathrm{H}_{2} \mathrm{SO}_{4}$ is used to remediate iodine from aqueous solution.

\section{EXPERIMENTAL}

Materials: Waste spinach leaves needed for the study were collected from agricultural lands and local vegetable markets of Janakpur, Nepal. Required chemicals were obtained from different manufacturers mentioned at particular places, and the reagents were $A R / L R$ grades and were used without further purification. 
Preparation of adsorbent from spinach leaves: The spinach leaves sample was washed with distilled water. The washed sample was dried in shadow until a constant weight was achieved. The dried sample was ground to obtain a fine powder. The powdered sample was stored in a labeled container, and it was abbreviated as DSL (dry spinach leaves powder). $30 \mathrm{~g}$ of dried DSL was mixed with $60 \mathrm{~mL}$ of concentrated sulfuric acid (96\%) in an $800 \mathrm{~mL}$ round bottom flask (The specific surface area of the adsorbent obtained from refluxing with $\mathrm{H}_{3} \mathrm{PO}_{4}$ was lower than that of $\mathrm{H}_{2} \mathrm{SO}_{4}$ [20]). The mixture was refluxed at $100{ }^{\circ} \mathrm{C}$ in an oil bath by three pathways. In the first case, it was refluxed continuously for 6 hours, and then it was left for 18 hours in contact with $\mathrm{H}_{2} \mathrm{SO}_{4}$ for further soaking. In the second and third cases, the same process was repeated for 2 and 3 days. After completion of the reaction, a black product obtained in each case was washed with distilled water repeatedly until neutrality. The neutral black products obtained were dried in a convection oven at $70{ }^{\circ} \mathrm{C}$ for 24 hours. The final products thus obtained were again ground to get a fine powder.

All the three black products containing acid - activated carbon as a major constituent was abbreviated as ASL-1 (acid - activated carbon prepared from spinach leaves powder with 1 day treatment), ASL-2 (acid - activated carbon prepared from spinach leaves powder with 2 days' treatment) and ASL-3 (acid - activated carbon prepared from spinach leaves powder with 3 days' treatment). The obtained amount of activated carbon was in the range of 5 to $5.5 \mathrm{~g}$ per $30 \mathrm{~g}$ of the dry spinach powder (i.e., the percentage yield was between 16.6 to 18.3) while the ash content was neither separated nor analyzed quantitatively.

Preparation of approximately $0.1 \mathrm{M}$ stock solution of iodine: $20 \mathrm{~g}$ of $\mathrm{KI}$ (Merck Life Science Private Limited, India) was dissolved in $400 \mathrm{~mL}$ of distilled water taken in a beaker. $12.8 \mathrm{~g}$ of A.R. grade iodine was dissolved in a previously prepared solution of $\mathrm{KI}$. The mixture was stirred with a glass rod continuously until the complete dissolution of iodine occurred. The resulting solution was then transferred in to $1000 \mathrm{~mL}$ volumetric flask. The volume was made up to mark with distilled water. The solution was made homogeneous by shaking, and then it was kept in the dark and cold place. Thus, the prepared solution was standardized using $\mathrm{K}_{2} \mathrm{Cr}_{2} \mathrm{O}_{7}$ (Merck Life Science Private Limited, India). Preparation of working solution of iodine: Working solutions of lower concentrations ranging from 50 to 900 ppm were prepared by the serial dilution of standardized stock solution of iodine (Merck Life Science Private Limited, India) with distilled water.

Preparation of reagents: Sodium thiosulphate solution (approx. $0.1 \mathrm{~N}$ ): $0.1 \mathrm{~N}$ sodium thiosulphate (Qualigens Fine Chemicals, India) was taken in a 250 $\mathrm{mL}$ volumetric flask and diluted up to the mark with distilled water. The prepared solution was standardized with $0.1 \mathrm{~N} \mathrm{~K}_{2} \mathrm{Cr}_{2} \mathrm{O}_{7}$ solution as a primary standard. It was then diluted to appropriate lower concentrations by dilution of stock solution with distilled water.

$\mathrm{KI}$ solution (approx. $10 \%$ ): About $10 \mathrm{~g}$ of A.R. grade potassium iodide was dissolved in distilled water in 100 $\mathrm{mL}$ volumetric flask and volume were made up to the mark. Starch solution (approx. 1\%): A paste of $1.0 \mathrm{~g}$ of soluble starch (Thomas Baker Chemicals Private Limited, India) was prepared with distilled water. This paste was then transferred in to a $100 \mathrm{~mL}$ of boiling distilled water in a beaker with constant stirring by a glass rod. The mixture was boiled until a clear solution was obtained, cooled, and stored in a stoppered bottle. The freshly prepared starch solution was used as far as it was possible. Buffer solutions of $\mathrm{pH} \mathrm{4.0,} \mathrm{7.0}$ and 9.2 were prepared by dissolving buffer tablets $(\mathrm{Hi}$ Media Laboratories Private Limited, India) in $100 \mathrm{~mL}$ volumetric flasks with distilled water.

Preparation of $1000 \mathrm{mg} / \mathrm{L}$ stock solution of methylene blue: $1.0 \mathrm{~g}$ of accurately weighed and dried methylene blue (Merck Life Science Private Limited, India) was dissolved in $1000 \mathrm{~mL}$ volumetric flask containing a little amount of distilled water, and then the volume was made up to mark with distilled water. The working solution of methylene blue was prepared by serial dilution of $1000 \mathrm{mg} / \mathrm{L}$ stock solution.

Determination of $\lambda_{\max }$ and calibration curve for methylene blue solution: First of all, $1000 \mathrm{mg} / \mathrm{L}$ stock solution was diluted to $100 \mathrm{mg} / \mathrm{L}$ with distilled water in a $250 \mathrm{~mL}$ volumetric flask by taking a $25 \mathrm{~mL}$ solution. After that, the resulting solution was diluted to 10 $\mathrm{mg} / \mathrm{L}$ in a $500 \mathrm{~mL}$ volumetric flask by taking a $50 \mathrm{~mL}$ solution, and the volume was made up to the mark with distilled water. From 100 ppm methylene blue solution, $2.5,5.0,7.5,10.0,12.5,17.5,20.0,22.5 \mathrm{~mL}$ solutions were prepared in $25 \mathrm{~mL}$ volumetric flask, respectively to prepare 1 to $9 \mathrm{ppm}$ solutions. The solution having intermediate concentration ( $5 \mathrm{mg} / \mathrm{L})$ was taken for the determination of $\lambda_{\max }$. The measurement was carried from 600 to $680 \mathrm{~nm}$ using a spectrophotometer (2306, Electronics, India) by setting the blank solution at zero absorbance. The maximum absorbance was obtained at $665 \mathrm{~nm}$. After finding out the value of $\lambda_{\max }$, the wavelength is set at $665 \mathrm{~nm}$, and the absorbance of the solution of different concentrations ( 1 to $10 \mathrm{mg} / \mathrm{L}$ ) was measured. Thus, the obtained plot between absorbance and concentration of the solution is known as a calibration curve for the methylene blue solution.

Characterization of adsorbent materials: The phase detection was done using X-ray Diffractometer with monochromatic $\mathrm{Cu} \mathrm{Ka}$ radiation (D2 phaser Diffractometer, Bruker, Germany, at Nepal Academy of Science and Technology NAST). Functional groups present in samples before and after adsorption of iodine were analyzed using Fourier transform infrared spectroscopy (IR Tracer 100, Shimadzu, Japan at Central Department of Chemistry, Tribhuvan University). Samples, before and after adsorption of iodine, were analyzed using optical microscopy (proCAM Radical 
Scientific India RXLr-4) to determine structural parts, subcomponents \& porosity of the adsorbent materials. Determination of specific surface area of the ASLs: The Langmuir adsorption isotherm model was used to determine the surface area of spinach leaf powder adsorbent material. For this $25 \mathrm{mg}$ of ASLs was added to the reagent bottle containing varying concentrations of methylene blue solutions from 10 to $300 \mathrm{mg} / \mathrm{L}$. The solutions were agitated in a mechanical shaker for 24 hours. After 30 minutes, the supernatant solutions were pipetted out. The absorbance of resultant supernatant solutions was measured at $665 \mathrm{~nm}$ using a spectrophotometer. The $\mathrm{Q}_{\max }$ value was calculated from Langmuir adsorption isotherm.

Adsorption studies: Effect of $\mathrm{pH}$ : Initially was determined an optimal concentration of iodine by trial error method and it was found to be $692 \mathrm{mg} / \mathrm{L}$. In order to study the effect of $\mathrm{pH}$ on iodine adsorption, 50 $\mathrm{mL}$ of $692 \mathrm{mg} / \mathrm{L}$ of iodine solution was poured in to a series of stoppered bottles and the $\mathrm{pH}$ of the solutions were varied from 2 to 10.5 using the $\mathrm{pH}$ meter with the help of $0.1 \mathrm{M} \mathrm{NaOH}$ and $0.1 \mathrm{M} \mathrm{HCl}$. Flasks containing $50 \mathrm{mg}$ of ASL-2 in each were shaken for 24 hours in a mechanical shaker at $220 \mathrm{rpm}$. After shaking, each equilibrated solution was filtered instantly using Whatman No. 41 filter paper. Direct titration method was used to determine the initial and equilibrium concentrations of iodine. In each case, the adsorption efficiency was determined with the help of the calculated value of initial and equilibrium concentration.

Effect of initial concentration: The effect of iodine concentration on the adsorption was studied under optimum pH. $50 \mathrm{mg}$ of ASL-2 was added to the 50 $\mathrm{mL}$ of iodine solution having initial concentrations ranging from 50 - $908 \mathrm{mg} / \mathrm{L}$. The equilibration time for iodine removal was less than 50 minutes for each. Each solution was agitated at $220 \mathrm{rpm}$ until the fulfillment of equilibration time. After shaking, each solution was filtered instantly using Whatman No. 41 filter paper. Direct titration method was used in order to determine the initial and equilibrium concentrations of iodine. In each case, the two most widely used models of Langmuir and Freundlich were tested for studying the adsorption isotherm.

Effect of reaction time: The effect of kinetics on the adsorption of iodine removal was studied. Here, $50 \mathrm{mg}$ of ASL-2 was added to the $50 \mathrm{~mL}$ of iodine solution having an initial concentration of 169.069 $\mathrm{mg} / \mathrm{L}$. The solution was agitated in a mechanical shaker at $220 \mathrm{rpm}$ for different time durations ranging from $5 \mathrm{~min}$. to 24 hours. After shaking, each solution was filtered instantly. Direct titration method was applied for the determination of initial and equilibrium concentrations of iodine. In each case, the data obtained were tested with pseudo-firstorder and pseudo - second - order kinetic models.

\section{RESULTS AND DISCUSSION}

Characterization of adsorbent materials:X-ray diffraction (XRD) analysis: The XRD pattern of raw spinach leaves to powder and the samples obtained by two days' treatment with concentrated sulfuric acid at $100{ }^{\circ} \mathrm{C}$ was recorded and is shown in Fig. 1.

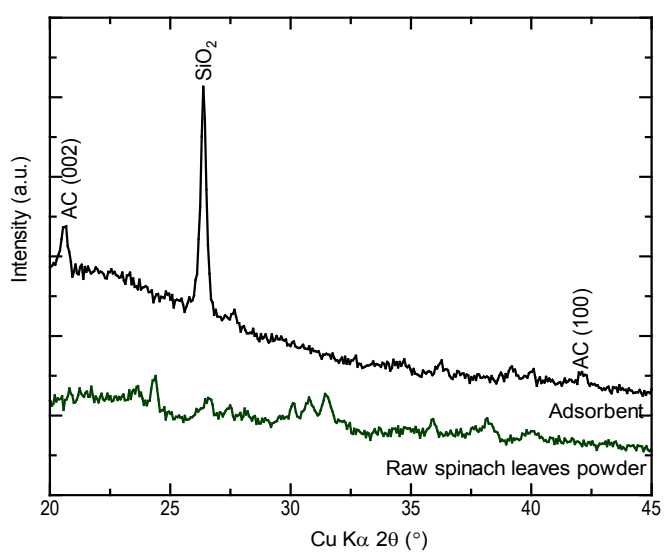

Fig. 1. XRD patterns of the raw sample (DSL) and spinach leaves powder adsorbent material (ASL-2)

The prepared sample was mostly amorphous showing weak and broad diffraction peaks of activated carbon at $2 \theta$ angles 23 and $42^{\circ}$ (JCPDS Card No. 41-1487), Sharp peak of $\mathrm{SiO}_{2}$ was obtained at $2 \theta$ angle $26.37^{\circ}$ (JCPDS Card No. 13-0026).

FTIR analysis: The main groups present in adsorbent were quantitatively analyzed using FTIR spectroscopy and shown in Fig. 2. Correspondence of respective metallic and non-metallic adsorption at the stretching and bending of active groups present in ASL were determined from the FTIR spectra of metal and nonmetal loaded ASL-2. The spectrum of raw spinach leaves powder (DSL) and spectra obtained from ASLs has broadband between $3298 \mathrm{~cm}^{-1}$ representing the $\mathrm{O}-\mathrm{H}$ bonded. Aliphatic $\mathrm{C}-\mathrm{H}$ stretching was obtained at 2914 and $2848 \mathrm{~cm}^{-1}$. The $\mathrm{C}=\mathrm{C}$ of arene was observed around $1600-1670 \mathrm{~cm}^{-1}$. The peak of C-O of ester, ether, and phenol was observed between 1300 and $1000 \mathrm{~cm}^{-1}$ [21].

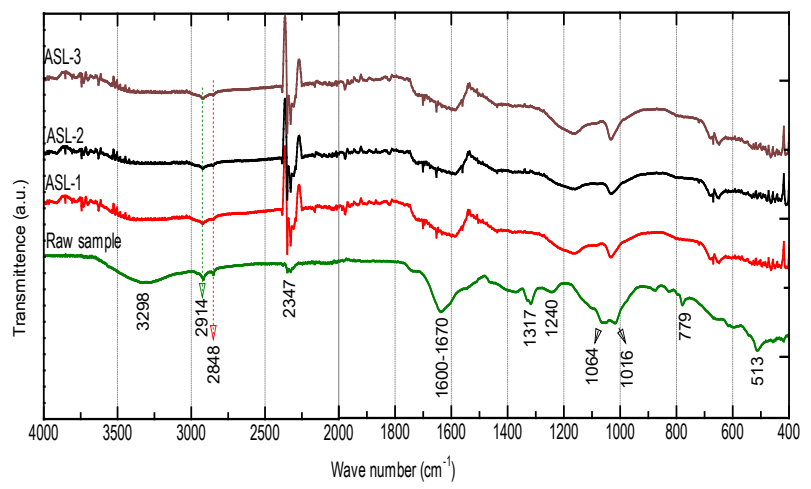

Fig. 2. FTIR spectra of raw spinach, ASL-1, ASL-2, and ASL-3 samples 
These obtained results revealed that bonded $\mathrm{O}-\mathrm{H}$ groups are present in an abundant amount in ASL, and these groups are responsible for adsorption. These groups in bio - char of adsorbent may serve as $\mathrm{H}^{+}$donor. Therefore, deprotonated bonded $\mathrm{O}-\mathrm{H}$ groups may be involved in coordination with metallic and non-metallic ions. The spectra analysis of ASLSs showed that there were a clear band shift and a decrease in intensity of the band at $3298 \mathrm{~cm}^{-1}, 2914 \mathrm{~cm}^{-1}$, and $1600 \mathrm{~cm}^{-1}$ in the sequence ASL-2 > ASL-3 > ASL-1. These are due to the high temperature in the activation process that broke some more intermolecular bonds in ASL-2 compared with ASL-1. Less satisfactory parameters for ASL-3 compared with ASL-2 may be due to an overdose of contact time of adsorbent with concentrated $\mathrm{H}_{2} \mathrm{SO}_{4}$. Hence, ASL-2 being the best adsorbent among 3 activated carbons, it was utilized for carrying out the adsorption process for the adsorption of iodine.

Optical microscopic images: Adsorbents before and after adsorption with iodine as well as raw sample were analyzed using an optical microscope. The resulting images at ten times magnification are shown in Fig. 3.
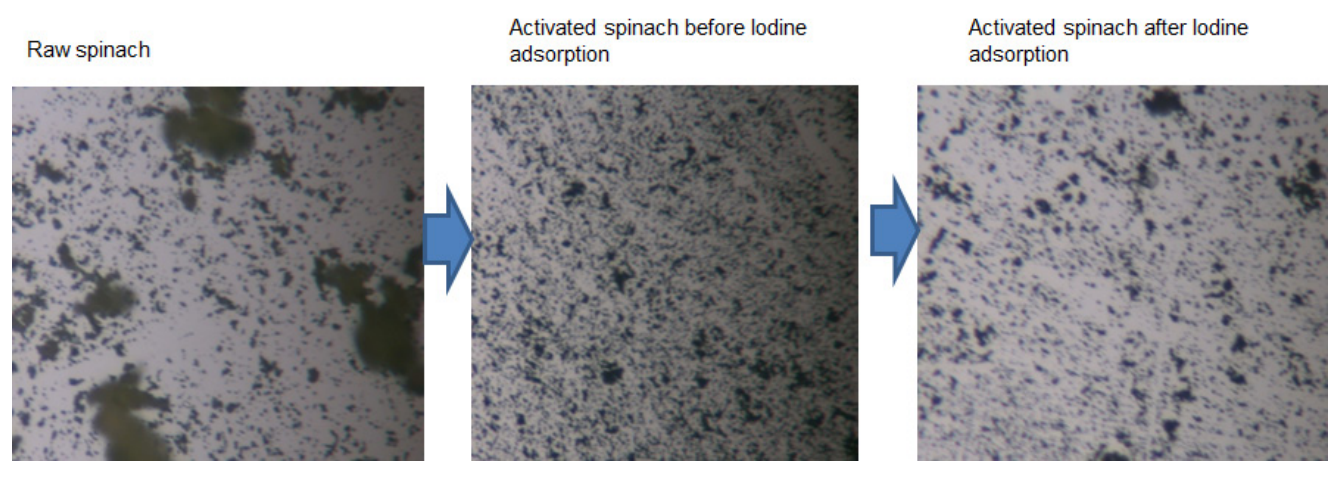

Fig. 3. Optical images of DSL and ASL-2 before and after adsorption of iodine

The optical image of the activated carbon indicated the presence of a homogeneously distributed pore structure, and this porous nature of adsorbent materials was found to decrease with the adsorption of iodine. Determination of $\lambda_{\max }$ for methylene blue solution: From the absorbance versus wavelength plot for the methylene blue solution, the maximum absorbance was observed at $665 \mathrm{~nm}$, which is in close agreement with the values reported in the literature [22].

Calibration curve of the methylene blue solution: The absorbance versus concentration plot for the methylene blue solution is shown in Fig. 4. It was found to be linear up to $10 \mathrm{ppm}$ and obeyed Beer - Lambert's law. In order to measure the absorbance of a highly concentrated methylene blue solution, further dilution was required.

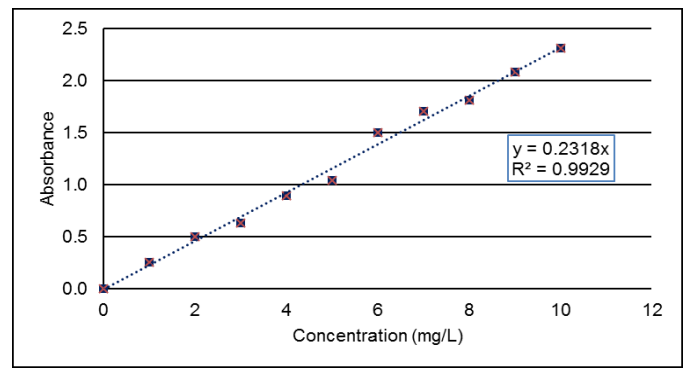

Fig. 4. A plot of absorbance as a function of the concentration of methylene blue solution

Specific surface area determination: For the determination of specific surface area, "Methylene blue adsorption method" was adopted widely for various natural solids such as activated carbon, charcoal, graphite, and silica, etc. [23]. This method is simple, rapid, easy, reliable, and cheap. Therefore, this method can be performed in any laboratory easily. In this method, a fixed amount of adsorbent is added to the different concentrations of methylene blue solution, and the specific surface area is determined by using Langmuir adsorption isotherm [23]. By assuming monolayer adsorption of methylene blue on to the surface of sorbent particle, the specific surface area is calculated as:

$$
S_{M B}=\frac{Q_{M A X} \cdot a_{M B} \cdot N}{M_{M B}}
$$

Where, $S_{M B}$ is the specific surface area in $\mathrm{m}^{2} / \mathrm{g}, \mathrm{Q}_{\max }$ is the mass in gram of methylene blue adsorbed per gram of sorbent, $a_{M B}$ is the area occupied by one molecule of methylene blue in $\mathrm{m}^{2} /$ molecule, $\mathrm{N}$ is the Avogadro's number $(6.023 \times 1023 \mathrm{molecules} / \mathrm{mol})$, and $\mathrm{M}$ is the methylene blue molar mass, i.e., $373.9 \mathrm{~g} / \mathrm{mol}$ $[23,24]$. Here, the $Q_{\max }$ is equivalent to the equilibrium adsorption capacity of the Langmuir equation.

From the slopes of linearized Langmuir curves (i.e., $\mathrm{C}_{\mathrm{e}}$ ' $Q_{e}$ as a function of $C_{e}$ ) for ASL-1, ASL-2, and ASL-3 the specific surface area of the adsorbent materials was determined. The specific surface area of the adsorbent materials is shown in the bar diagram of Fig. 5 .

The specific surface area values are in the range of 436, 499, and $476 \mathrm{~m}^{2} / \mathrm{g}$ for ASL-1, ASL-2, and ASL3 , respectively. The lowest surface area of $A S L-1$ in comparison with ASL-2 may be due to not completed of activation of spinach in one day while in case of 3 days 


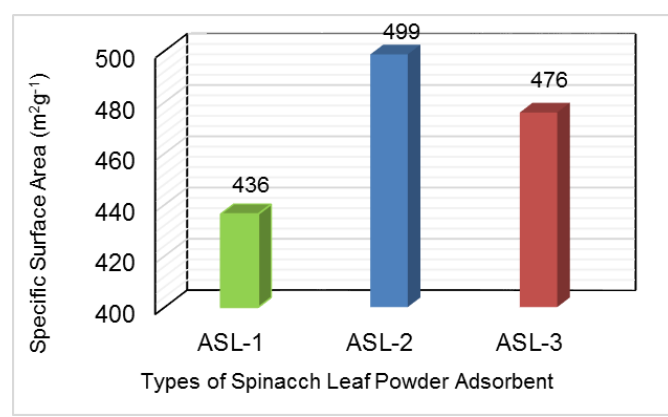

Fig. 5. Comparative study of specific surface area on different adsorbents.

activation, more ash content was formed, which may have blocked the pores of the adsorbent ASL-3.

Effect of $\mathbf{p H}$ : The results obtained for the adsorptive removal of iodine as a function of $\mathrm{pH}$ are presented in Fig. 6. The adsorption yield of adsorbent was changed when the $\mathrm{pH}$ of a solution containing iodine was increased continuously. Adsorption \% and adsorption capacities were observed the maximum at $\mathrm{pH} 10$ and minimum at 11.5 for iodine. In general, at low $\mathrm{pH}$, concentration, and mobility of $\mathrm{H}^{+}$ions are high. So they get preferentially adsorbed on the adsorbent rather than the other adsorbate molecules. Hence, adsorption of lodine ions at very low $\mathrm{pH}$ was found the minimum.

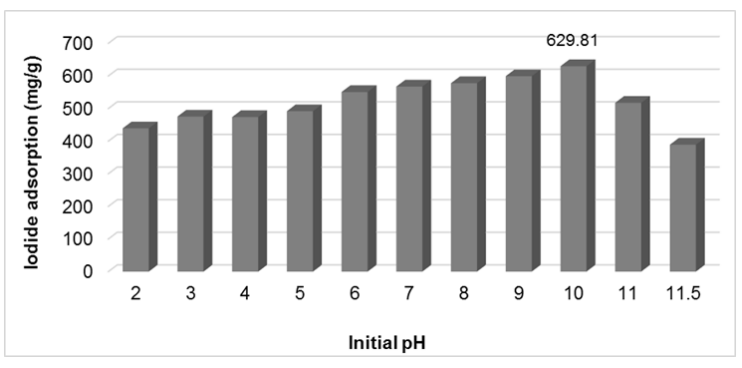

Fig. 6. Effect of pH for the adsorption of iodine on to the adsorbent ASL-2

Among various species such as $\mathrm{I}_{2}, \mathrm{I}^{-}$, and $I_{3}^{-}$that are present in the aqueous iodine solution, at alkaline $\mathrm{pH}$ or in the presence of $\mathrm{NaOH}$ small amount of $\mathrm{I}_{2}$ that present in the solution react with $\mathrm{I}^{-}$to form $\mathrm{I}_{3}^{-}$[25]. The experimental optimum equilibrium $\mathrm{pH}$ value for iodine adsorption was 10. The fluctuation of experimental optimum $\mathrm{pH}$ value with respect to reference value may be due to the adsorption of iodine in the form of $\mathrm{I}_{3}^{-}$. The decrease in iodide adsorption below this $\mathrm{pH}$ value may be due to the combined effect of blocking of adsorption sites with a huge number of $\mathrm{H}^{+}$ions and lowering of the lodide content in the solution below initial $\mathrm{pH} 8$. The decrease in iodide adsorption at an equilibrium $\mathrm{pH}$ value greater than 10 may be due to desorption of $\mathrm{I}_{2}$ at higher concentration of $\mathrm{NaOH}$ resulted due to inter ionic repulsion in between the iodide ions and hydroxyl ions.

Batch adsorption isotherm studies: In 1918, Langmuir gave a relation between the amount adsorbed and the concentration for a unimolecular layer and is known as Langmuir adsorption isotherm [26]. Langmuir assumed monolayer surface coverage of adsorbent molecules with energetically equivalent adsorption sites where there was no interaction between the adsorbed molecules. The general form of equation representing the Langmuir's adsorption isotherm is given as:

$$
Q_{\theta}\left(=\frac{X}{M}\right)=\frac{b Q_{\max } C_{\theta}}{1+b C_{\theta}}
$$

Where, $Q_{e}$ is equilibrium adsorption capacity $(\mathrm{mg} / \mathrm{g})$, $X$ is the mass of adsorbate $(\mathrm{mg}), \mathrm{M}$ is the mass of adsorbent (g), $Q_{\max }$ is maximum adsorption capacity $(\mathrm{mg} / \mathrm{g}), \mathrm{b}$ is a constant related to adsorption energy (L/ $\mathrm{mg}$ ) and $\mathrm{C}_{\mathrm{e}}$ is the equilibrium concentration of the ions adsorbed (mg/L).

The linearized form of equation (2) is:

$$
\frac{C_{e}}{Q_{\theta}}=\frac{1}{Q_{\max } b}+\frac{C_{\theta}}{Q_{\max }}
$$

Thus, $C_{b} / Q_{b}$ values are plotted as ordinate against $C_{e}$ as abscissa to $1 / Q_{\max }$ get a straight line with a slope equal to and intercept on the ordinate equal to $1 / Q_{\max } b$. Here, slope and intercept are used for the determination of $Q_{\max }$ and $b$, respectively. The essential characteristics of the Langmuir isotherm can be explained in terms of a dimensionless separation factor $\left(\mathrm{K}_{\mathrm{L}}\right)$ which describes the type of isotherm, as defined by [27].

$$
K_{L}=\frac{1}{1+b C_{i}}
$$

Where, $\mathrm{C}_{i}$ is the initial concentration of the adsorbate in $\mathrm{mg} / \mathrm{L}$ and $\mathrm{K}_{\mathrm{L}}$ is the Langmuir equilibrium parameter. Shape of isotherm and nature of adsorption process is indicated by $K_{L},\left[K_{L}>1\right.$, unfavorable, $K_{L}=1$, linear, $0<K_{L}<1$, favorable, $K_{L}=0$, irreversible]. Hence, for favorable isotherms, the $\mathrm{K}_{\mathrm{L}}$ value should lie between 0 and $1[28,29]$.

Freundlich adsorption isotherm: Freundlich, in 1909, proposed an empirical equation to represent, in general, the adsorption relationship and is classically called Freundlich adsorption isotherm. According to Freundlich, the heterogeneous adsorbent surface containing a non-uniform distribution of heat of adsorption is suggested to adsorb more than one ion per binding site forming multilayer adsorption [30]. It is expressed as:

$$
Q_{\theta}=K_{F} C_{\theta}^{\frac{1}{n}}
$$

Where: $Q_{e}$ is the amount of adsorbate adsorbed per unit mass of adsorbent $(\mathrm{mg} / \mathrm{g}), \mathrm{C}_{\mathrm{e}}$ is the equilibrium concentration of the adsorbate $(\mathrm{mg} / \mathrm{L}), \mathrm{K}_{\mathrm{F}}$, and $\mathrm{n}$ are Freundlich isotherm constants related to adsorption 
capacity and intensity of adsorption respectively. The value of $1 / \mathrm{n}$ generally lies between 0 and 1 . On taking logarithms on both sides of equation (5),

$$
\log Q_{\theta}=\log K_{F}+\frac{1}{n} \log C_{\theta}
$$

Thus, $K_{F}$ and $n$ can be determined, if the values of $\log Q_{e}$ are plotted as ordinate against $\log \mathrm{C}_{\mathrm{e}}$ as abscissa. The slopes and intercepts of the linearized Langmuir and Freundlich plots were used to calculate the Langmuir and Freundlich parameters and tabulated as shown in Table 1.

Table 1. Parameters of Langmuir and Freundlich constants of lodine adsorption.

\begin{tabular}{lcccc}
\hline \multicolumn{5}{c}{ Langmuir model } \\
\hline$Q_{\max }(\mathrm{mg} / \mathrm{g})$ & $\mathrm{b}(\mathrm{L} / \mathrm{mg})$ & $\mathrm{R}^{2}$ & $\Delta \mathrm{G}(\mathrm{kJ} / \mathrm{mol})$ & $\mathrm{X}^{2}$ \\
909.091 & 0.196 & 0.9994 & -25 & 8.29 \\
\multicolumn{5}{c}{ Freundlich model } \\
$K_{\mathrm{F}}\left[(\mathrm{mg} / \mathrm{g})(\mathrm{L} / \mathrm{mg})^{1 / n}\right]$ & $\mathrm{n}$ & $\mathrm{R}^{2}$ & $\mathrm{X}^{2}$ \\
\hline 296.10 & & 3.86 & 0.9289 & 39.44 \\
\hline
\end{tabular}

lodine adsorption versus equilibrium concentration plot for $\mathrm{I}_{2}$ is shown in Fig. 7. Langmuir isotherm was better fitted by the isotherm data in comparison with Freundlich isotherm. Therefore, adsorption on the surface of ASL2 was monolayer adsorption with a very high coefficient of determination $\left(R_{2}=0.9994\right)$. The maximum uptake capacity $\left(Q_{\max }\right)$ for $I_{2}$ was $909.091 \mathrm{mg} / \mathrm{g}$. The obtained $Q_{\max }$ value was significantly higher than most of the other adsorbent reported in the literature.

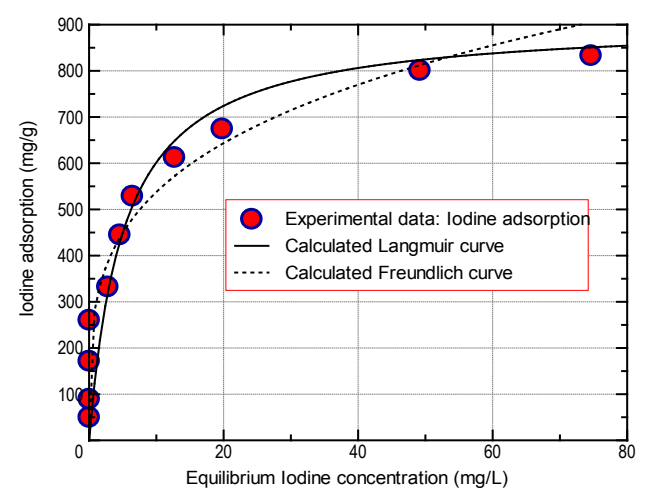

Fig. 7. The adsorption isotherm of iodine onto activated carbon obtained from spinach

Error analysis for isotherm studies: In order to evaluate the fit between experimental data and the various isotherm models, linear regression is the widely used approach where the closeness of the fit is determined from the value of the coefficient of determination $\left(R_{2}\right)$. Linear regression analysis, however, transforms nonlinear isotherm equations in to their linearized forms and this transformation violates the error variance and normality assumptions of standard least squares. In this sense, the non-linear chi-square analysis, $x^{2}$, shown in equation (7) can give more accurate results since this method compares all isotherms on the same abscissa and ordinate [28].

$$
\chi^{2}=\sum \frac{\left(Q_{\theta, c a l}-Q_{\theta, e x p}\right)^{2}}{Q_{\theta, c a l}}
$$

where, $Q_{B, C A L}$ is the equilibrium capacity obtained from expressions describing the different models $(\mathrm{mg} / \mathrm{g})$ and $Q_{B, B \times P}$ is the equilibrium capacity $(\mathrm{mg} / \mathrm{g})$ obtained from the experimental data. Smaller $\mathcal{X}^{2}$ values confirm a better correspondence between obtained data and isotherm model. In addition, non-linear chi-square analysis can also be used in the case where linear regression analysis leads to inadequate conclusions [28]. The smaller value of $x^{2}$ for the Langmuir model than that of the Freundlich model also confirmed the Langmuir adsorption isotherm as the best fitting model in each case. From Table 1, $\Delta \mathrm{G}$ value calculated was - $25 \mathrm{~kJ} /$ mol. The negative value for free energy $(\Delta G)$ confirmed the spontaneous, physico - chemical adsorption of $\mathrm{I}_{2}$ on ASL-2. The $\mathrm{K}_{\mathrm{L}}$ values obtained from Eqn. (7) for $\mathrm{I}_{2}$ adsorption with using Langmuir, parameters were in the ranges between 0.01 to 0.09 which are between 0 and 1 , indicating favorable adsorption.

Batch kinetic studies: A number of adsorption kinetic models have been introduced in order to investigate the reaction kinetics. Among them, pseudo-first-order and pseudo-second-order kinetic models are the most frequently used models. The adsorption capacity can also be used to describe the adsorption mechanism of the metal ions on the adsorbent surface where it is difficult to analyze using correlation coefficient values [31].

Pseudo-first-order kinetic model: Pseudo-first- order kinetic model states that the rate of adsorption at any time $(\mathrm{dQ} / \mathrm{dt})$ is directly proportional to the amount of remaining unoccupied surface site (i.e. $Q_{e}-Q_{t}$ ). The differential form of pseudo-first-order rate equation (Lagergren, 1898) is generally expressed as below [32]:

$$
\frac{d Q}{d t}=K_{1}\left(Q_{\theta}-Q_{t}\right)
$$

Where, $Q_{e}$ and $Q_{t}$ are the amounts of adsorbate adsorbed per unit weight $(\mathrm{mg} / \mathrm{g})$ of adsorbent at equilibrium and at the time $(\mathrm{t})$, respectively and $\mathrm{K}_{1}$ $\left(\mathrm{min}^{-1}\right)$ is the first order Lagergren adsorption rate constant. The linearized form of the equation obtained by integrating equation (8) for the boundary conditions $t=0$ to $t=t$ and $Q_{t}=0$ to $Q_{t}=Q_{t}$ is given as:

$$
\log \left(Q_{\theta}-Q_{t}\right)=\log Q_{\theta}-\frac{K_{1}}{2.303} \times t
$$

Hence, $Q_{e}$ and $K_{1}$ can be calculated from the slope and intercept of the graph plotted between $\log \left(Q_{e}-Q_{t}\right)$ and time. 
Pseudo-second-order kinetic model: Pseudo-second -order kinetic model states that the rate of adsorption at any time $(\mathrm{dQ} / \mathrm{dt})$ is directly proportional to the square of the amount of remaining unoccupied surface sites [i.e. $\left(Q_{e}-Q_{t}\right)^{2}$ ] [33]. Therefore, the generalized form of kinetic rate law can be written as follows:

$$
\frac{d Q}{d t}=K_{2}\left(Q_{\theta}-Q_{t}\right)^{2}
$$

Where, $Q_{e}$ and $Q_{t}$ are the amount of adsorbate adsorbed per unit weight of adsorbent $(\mathrm{mg} / \mathrm{g})$ at equilibrium and at the time $(\mathrm{t})$, respectively and $\mathrm{K}_{2}(\mathrm{~g} /$ $\mathrm{mg} \cdot \mathrm{min}$ ) is the pseudo-second-order adsorption rate constant. The linearized form of the equation obtained after integrating for the boundary conditions $t=0$ to $t$ and $Q_{t}=0$ to $Q_{t}$, and rearranging of the integrated rate law for a pseudo-second-order reaction is given as:

$$
\frac{t}{Q_{t}}=\frac{1}{K_{2} Q_{\theta}^{2}}+\frac{t}{Q_{\theta}}
$$

Where, $t$ is contact time and $h\left(=K^{2} Q_{e}{ }^{2}\right)$ is the initial adsorption rate $(\mathrm{mg} / \mathrm{g} \cdot \mathrm{min})$. Hence, $K_{2}$ and $Q_{e}$ values can be calculated from the slope and intercept of the graph plotted between $\left(t / Q_{t}\right)$ and $t$. The kinetic parameters obtained from the slope and intercepts of pseudo-first and pseudo-second-order rate equations for the adsorption of iodine on to the activated carbon obtained from spinach leaves (ASL-2) are presented in the following Table 2.

Table 2. The order and rate constants for the adsorption of $\mathrm{I}_{2}$ on to ASL-2.

\begin{tabular}{ccccccc}
\hline Order & Slope Intercept & $\begin{array}{c}\mathbf{K}_{1} \\
\left(\mathbf{m i n}^{-1}\right)\end{array}$ & $\begin{array}{c}\mathbf{K}_{2} \\
(\mathbf{g} / \mathbf{m g} \cdot \mathbf{m i n})\end{array}$ & $\begin{array}{c}\mathbf{Q e} \\
(\mathbf{m g} / \mathbf{g})\end{array}$ & $\mathbf{R}^{2}$ \\
\hline $1^{\text {st }}$ & 0.0111 & 1.4317 & 0.0256 & - & 4.186 & 0.9532 \\
$2^{\text {nd }}$ & 0.0059 & 0.0114 & - & 0.00305 & 169.5 & 0.9996 \\
\hline
\end{tabular}

The kinetic curve representing the equilibrium adsorption capacity versus time is shown in Fig. 8. The amount of adsorption is sharply increased with increasing contact time in the initial stage for $\mathrm{I}_{2}$ and then gradually increased to reach an equilibrium value in less than 50 minutes. A negligible effect on the amount of adsorption was observed on further increasing contact time. The initial sharp increase of adsorption capacity is due to the availability of a greater number of active sites at the initial stage. The number of active sites decreases with time due to adsorption and it reaches an equilibrium value after a certain interval of time. Therefore, the equilibrium adsorption capacity was gradually increased to reach equilibrium after a certain interval of time.

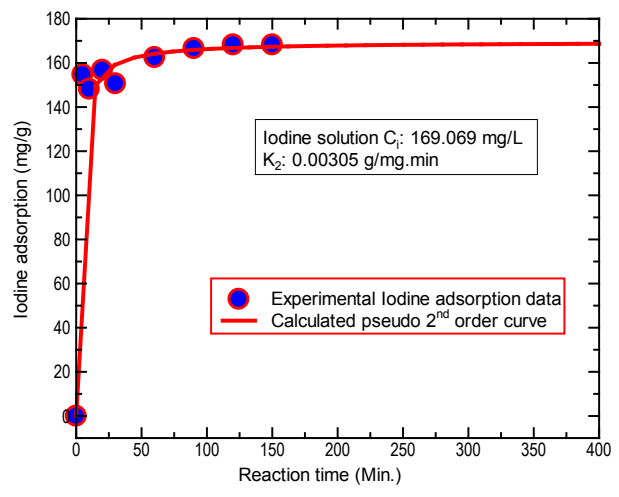

Fig. 8. Kinetic plots for the adsorption of lodine on ASL-2

Mechanism of iodine adsorption: The maximum adsorption at $\mathrm{pH} 10$ and the free energy of adsorption $(\Delta \mathrm{G})$ in the range of $-25 \mathrm{~kJ} / \mathrm{mol}$ indicate the complex pattern of adsorption mechanism involving more than one mechanism. In aqueous solution, iodine can be present in three species, such as elemental $\left(\mathrm{I}_{2}\right), \mathrm{I}^{-}$and $\mathrm{I}_{3}^{-}$. The $\mathrm{I}_{3}{ }^{-}$is expected to be stable under very oxidized conditions, whereas elemental iodine is stable at moderately oxidized, acidic conditions [34]. Thus, it is expected that the adsorptive species of iodine on the present adsorbent at $\mathrm{pH} 10$ is $\mathrm{I}_{3}^{-}$and is in agreement with a previous report [35]. The adsorption process is followed by both physisorption and chemisorption. Loosely bonded hydroxyl groups available for the ion exchange process are responsible for chemisorption while, the pores available in activated carbon are responsible for physisorption (The analysis of the FTIR spectra of the activated carbon before and after the adsorption of iodine is shown in Fig. 10). At $\mathrm{pH} 10$ there is some amount of $\mathrm{NaOH}$ present in the solution which reacts with iodine as:

$$
\mathrm{I}_{2}+2 \mathrm{NaOH} \rightarrow \mathrm{NaI}+\mathrm{NaIO}+\mathrm{H}_{2} \mathrm{O}
$$

On porous adsorbents, overall adsorption processes are controlled either by film diffusion (external mass transfer of adsorbate from solution to the external surface of the adsorbent) alone or, in combination with pore diffusion (intraparticle mass transfer of adsorbate in to the adsorbent pores). The intraparticle diffusion model proposed by Weber and Morris identifies the process explaining rate-determining step. The general form of the equation used is shown in equation (13).

$$
Q_{t}=K_{i d} t^{0.5}+C
$$

Where, $\mathrm{K}_{\mathrm{id}}\left(\mathrm{mg} / \mathrm{gh}^{0.5}\right)$ is the intraparticle diffusion rate constant. The $\mathrm{K}_{\text {id }}$ and $\mathrm{C}$ can be calculated from the slope and intercept of the graph plotted between $Q_{t}$ and $t^{0.5}$. The intercept of the plot describes the boundary layer effect. The contribution of the surface adsorption in the rate - controlling step increases if the intercept of the plot increases. The intraparticle diffusion model is most satisfactorily explained if, $Q_{t}$ varies linearly with $t^{0.5}$ 
by passing through the origin. If the whole plot doesn't pass through the origin, it indicates that the mechanism of intraparticle diffusion is not only the rate-limiting step of the adsorption process. The multiple linear sections in the plot indicate the involvement of other interaction mechanisms [36, 371. A plot of iodine uptake versus square root of time $(\sqrt{t})$ is shown in Fig. 9. The $Q_{t}$ versus $(\sqrt{t})$ plot for each ion does not pass through the origin, showing that the intraparticle diffusion model was not the rate-limiting step. The $\mathrm{K}_{\mathrm{id}}$ and $\mathrm{R}^{2}$ values obtained from the plot are 1.9464 and 0.9095 respectively.

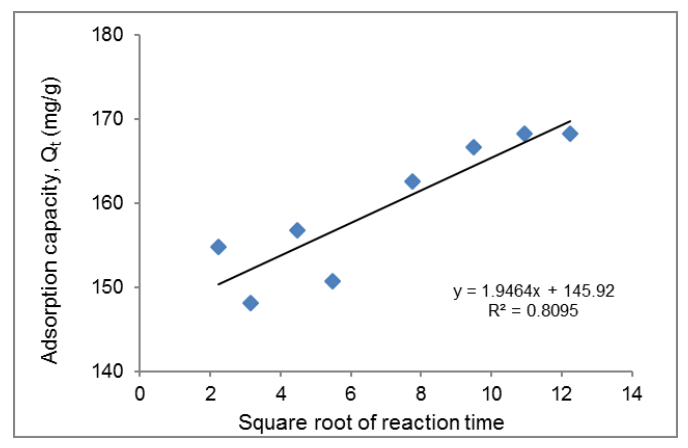

Fig. 9. The plot of $Q_{t}$ versus $(\sqrt{t})$ for the adsorption of iodine on ASL-2

The FTIR spectra of the activated carbon before and after the adsorption of iodine are shown in the following Fig. 10.

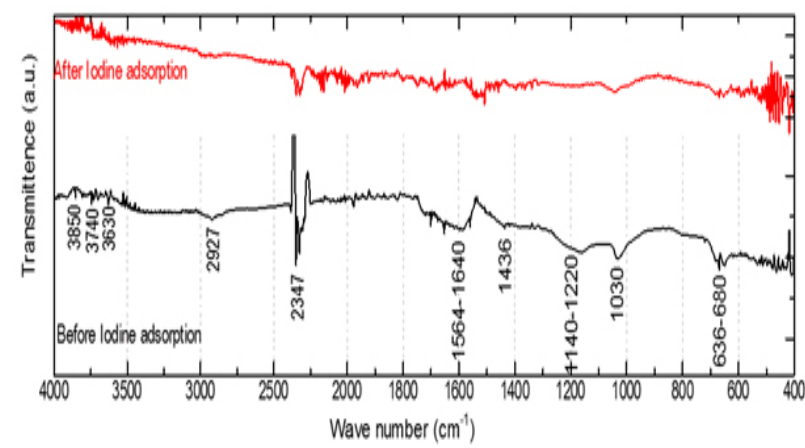

Fig. 10. FTIR Spectra of activated carbon obtained from the spinach before and after lodine adsorption

No broadband of hydroxyl peak was detected in the spectra obtained after the adsorption of iodine ions, even in the range $3280-3460 \mathrm{~cm}^{-1}$. This diminishing of hydroxyl peak after adsorption may be due to the involvement of the hydroxyl group in the adsorption process. A clear peak of $\mathrm{C}=\mathrm{C}$ of arene and $\mathrm{C}-\mathrm{O}-\mathrm{C}$ linkage at 1564-1640 $\mathrm{cm}^{-1}$ and $1030 \mathrm{~cm}^{-1}$ in ASL-2 are diminished after iodine adsorption showing that $\mathrm{C}=\mathrm{C}$ of arene interacts with the generated iodine species and cross-linking between hydroxyl groups of different polyphenols are no longer stable after iodine adsorption. Peaks of background $\mathrm{CO}_{2}$ seen at $2200-2400 \mathrm{~cm}^{-1}$ were mostly diminished after iodine ions adsorption showing that iodine ions are preferentially adsorbed on the adsorbent expelling out $\mathrm{CO}_{2}$ from their adsorption sites.

\section{CONCLUSION}

In this study, low-cost adsorbent materials were prepared from waste spinach leaves by chemical treatment with conc. $\mathrm{H}_{2} \mathrm{SO}_{4}$. Adsorbent materials were characterized with various tools and techniques available. The adsorption of $\mathrm{I}_{2}$ was a $\mathrm{pH}$-dependent process and was found maximum at $\mathrm{pH} 10$. The equilibration time for adsorption of iodine on ASL-2 was less than 50 minutes. The adsorption data followed pseudo-second-order kinetics with a rate constant of $0.00305 \mathrm{~g} /(\mathrm{mg} \cdot \mathrm{min})$, indicating chemisorption as the rate-limiting mechanism. The equilibrium adsorption capacity determined from the Langmuir model was $909.091 \mathrm{mg} / \mathrm{g}$. The negative $\Delta \mathrm{G}$ value of $-25 \mathrm{~kJ} / \mathrm{mol}$ obtained from Langmuir equation indicated that the adsorption process was a spontaneous, feasible, and physio-chemical type.

\section{REFERENCES}

1. Martinez N. (2014) Selected techniques in radioecology: model development and comparison for internal dosimetry of rainbow trout (Oncorhynchus mykiss) and feasibility assessment of reflectance spectroscope use as a tool in phytoremediation, Ph.D. Thesis, Colorado State University, USA.

2. Anzai K., Ban N., Ozawa T., Tokonami S. (2012) Fukushima Daiichi nuclear power plant accident: facts, environmental contamination, possible biological effects and countermeasures. J. Clin. Biochem. Nutr., 50, 2-8. https://doi.org/10.3164/ jcbn.D-11-00021

3. Belson K., Tabuchi, H. (March 19, 2011) Japan finds tainted food up to 90 miles from nuclear sites, The New York Times. https://www.nytimes. com/2011/03/20/world/asia/20japan.html

4. Hirota M., Higaki S., Higaki T., Hasezawa S. (2013) Investigation of contamination in spinach collected immediately following the Fukushima Daiichi nuclear disaster, Radiat. Saf. Manag., 12, 43-47. https://doi.org/10.12950/rsm.12.435

5. National Research Council. Health Implications of Perchlorate Ingestion, The National Academies Press, Washington DC (USA) 2005, 1-4. https://doi.org/10.17226/11202).

6. Dal Maso L., Bosetti C., La Vecchia C., Franceschi S. (2009) Risk factors for thyroid cancer an epidemiological review focused on nutritional actors. Cancer Causes Control, 20(1), 75-86. https://doi.org/10.1007/s10552-008-9219-5

7. Fukoda S., Iwamoto K., Atsumi M., Yokoyama A., Nakayama T., Ishida K., Inouye I., Shiraiwa Y. (2014) Global searches for microalgae and aquatic plants that can eliminate radioactive cesium, iodine and strontium from the radio-polluted aquatic environment: a bioremediation strategy. J. Plant Res., 127, 79-89. https://doi.org/10.1007/s10265013-0596-9 
8. Tan X., Liu, Y., Zeng, G., Wang, X., Hu, X., Gu, Y., Yang, Z. (2015) Application of biochar for the removal of pollutants from aqueous solutions. Chemosphere, 125, 70-85. https://doi. org/10.1016/j.chemosphere.2014.12.058

9. Galla N.R., Pamidighantam P.R., Balaswami K., Gurusiddaiah M.R., Akula S. (2017) Nutritional, the textural and sensory quality of biscuits supplemented with spinach (Spinacia oleracea L.), Int. J. Gastron. Food Sci., 7, 20-26. https://doi.org/10.1016/j.ijgfs.2016.12.003

10. Kaghazchi T., Kolur N.A., Sabet R.H. (2009) Recovery of iodine with activated carbon from dilute aqueous solutions. AFINIDAD LXVI, 542, Julio-Agosto, 338-343.

11. Institute of Medicine, Food and Nutrition Board, Dietary reference intakes for vitamin A, Vitamin $\mathrm{K}$, arsenic, boron, chromium, copper, iodine, iron, manganese, molybdenum, nickel, silicon, vanadium and zinc. National Academies Press Washington DC (USA), 2001, 258-284. https://doi.org/10.17226/10026

12. McLane M.M. Newsom R.A. (1977) Recovery of iodine. United States Patent No 4036940.

13. Schneider C.A., Schneider D.J. (2011) lodine extraction process. United States Patent No 0108486 A1.

14. Keblys K.A., McEven J.M., and Orion L. (1978) lodine recovery process. United States Patent No 4131645.

15. Herkelmann R., Rudolph W., Seffer D. (1994) Method of recovering iodine, United States Patent No 5356611.

16. Venkat E., Magliette R.J., McKinney D., Michaels A.S. (2002) Recovery of iodide from Chemical process wastewater. United States Patent No 6379556 B1.

17. Singhal J.P., Ray A.R. (2002) Adsorption of iodine on nylon 6. Trends Biomate. Artif. Organs, 16(1), 46-51.

18. Klimaviciute R., Bendoraitiene J., Rutkaite R., Danilovas P.P. (2011) Adsorption of iodine on cationic cross-linked starches. Chemija, 22, 188-196. http://mokslozurnalai.Imaleidykla.It/ publ/0235-7216/2011/4/188-196.pdf

19. Itodo A.U., Abdulrahman F.W., Hassan L.G., Maigandi S.A., Itodu H.U. (2010) Application of methylene blue and iodine adsorption in the measurement of specific surface area by four acid and salt treated activated carbons. N. Y. Sci. J., 3(5), 25-33. http://www.sciencepub.net/newyork

20. Das B. (2019) Uptake of lead and arsenic ions by the adsorbent material obtained from physiochemical modification of spinach oleracea (spinach) leaves, Master's Thesis, Tribhuvan University, Nepal.

21. Smith B.C. (2017) The C-O bond, Part I: Introduction and the infrared spectroscopy of alcohols. Spectroscopy, 32 (1), 14-21.
22. Thapa S., Pokhrel M.R. (2012) Removal of As(III) from aqueous solution using $\mathrm{Fe}$ (III) loaded pomegranate waste. J. Nep. Chem. Soc., 30, 2936. https://doi.org/10.3126/jncs.v30i0.9332

23. Kaewprasit C., Hequet E., Abidi N., Goourlot J.P. (1998) Application of methylene blue adsorption to cotton fiber specific surface area measurement: Part I: Methodology. J. Cotton Sci., 2, 164-173. https://www. cotton.org/journal/1998-02/4/upload/jcs02-164.pdf

24. Vilar V.J.P., Botelho C.M.S., Boaventura R.A.R. (2007) Methylene blue adsorption by algal biomassbased materials: Biosorbent characterization and process behavior. J. Hazard. Mater., 147, 120-132. https://doi.org/10.1016/j.jhazmat.2006.12.055

25. Wren, J.C., Paquette J., Sundar S., Ford B.L. (1986) lodine chemistry in the +1 oxidation state. II. A Raman and UV-visible spectroscopic study of the disproportionation of hypoiodite in basic solutions. Can. J. Chem., 64, 2284-2296. https://doi.org/10.1139/v86-375

26. Langmuir I.J. (1918) The adsorption of gases on plane surfaces of glass, mica and platinum. J. Am. Chem. Soc., 40, 1361-1403. https://doi.org/10.1021/ja02242a004

27. Hall K.R., Eagleton L.C., Acrivos A. and Vermeulen T. (1966) Pore- and solid-diffusion kinetics in fixedbed adsorption under constant pattern conditions. Ind. Eng. Chem. Fundam., 5(2), 212-223. https://doi.org/10.1021/i160018a011

28. Karmacharya M.S., Gupta V.K., Tyagi I., Agarwal S., Jha, V.K. (2016) Removal of As(III) and As(V) using rubber tire-derived activated carbon modified with alumina composite. J. Mol. Liq., 216, 836-844. https://doi.org/10.1016/j.molliq.2016.02.025

29. Babaee Y., Mulligen C.N., Rahaman M.S. (2017) Removal of arsenic (III) and arsenic (V) from aqueous solutions through adsorption by $\mathrm{Fe} / \mathrm{Cu}$ nanoparticle. J. Chem. Technol. Biot., 93(1), 63-71. https://doi.org/10.1002/jctb.5320

30. Freundlich H., Heller W. (1939). The adsorption of cis- and trans-Azobenzene. J. Am. Chem. Soc., 61, 2228-2230. https://doi.org/10.1021/ja01877a071

31. Schiewer S., Balaria A. (2009) Biosorption of Pb2+ by original and protonated citrus peels, equilibrium, kinetics and mechanism. Chem. Eng. J., 146, 211219. https://doi.org/10.1016/j.cej.2008.05.034

32. Lagergren S. (1898) Zur theorie der sogenannten adsorption geloster stoffe. Kungliga svenska vetenskapsakademiens. Handlingar, 24, 1-39.

33. Ho Y.S. and McKay G. (1999) Pseudo-second order model for sorption processes. Process Biochem., 34(5), 451-465. https://doi.org/10.1016/ S0032-9592(98)00112-5

34. Kaplan D.I., Denham M.E., Zhang S., Yeager C., Xu C., et al. (2014) Radioiodine biogeochemistry and prevalence in groundwater. Crit. Rev. Environ. Sci. Technol., 44(20), 2287-2335. https://doi.org10.1080/10643389.2013.828273 
35. Kodama S., Takahashi Y., Okumura K., Uruga T. (2006) Speciation of iodine in solid environmental samples by iodine K-edge XANES: Application to soils and ferromanganese oxides. Sci. Total Environ., 363, 275-284. https://doi.org/10.1016/j.scitotenv.2006.01.004

36. Karmacharya M.S. (2016) Physicochemical characteristics of activated carbon obtained from the waste tire and its alumina composite. Ph.D. Thesis, Tribhuvan University, Nepal.
37. Nikic J., Agbaba J., Watson M.A., Tubic A., Solic M., Maletic S., Dalmacija B. (2019) Arsenic adsorption on Fe-Mn modified granular activated carbon (GAC-FeMn): batch and fixed-bed column studies. J. Environ. Sci. Heal A, 54(3), 168-178. https://doi.org/10.1080/10934529.2018.1541375 